\title{
Kurs i basale kirurgiske ferdigheter
}

\begin{abstract}
BAKGRUNN På Basic Surgical Skills (BSS)-kurset gjennomgås grunnleggende kirurgiske teknikker. Kurset ble første gang avholdt i Norge i 2009. Denne studien ble gjennomført for å evaluere læringsutbyttet av kurset.
\end{abstract}

MATERIALE OG METODE Deltakere fra fire påfølgende kurs ble forespurt om å delta i studien og ble testet $\mathrm{i}$ tre praktiske øvelser umiddelbart før og etter kurset. Prestasjonene ble målt ved hjelp av Objective Structured Assessment of Technical Skills (OSATS) på to av øvelsene og tidsbruk på den siste. I tillegg gjennomførte deltakerne to selvevalueringer av de gjennomgåtte øvelsene, én før og én etter kurset.

RESULTATER Totalt 57 av 65 kursdeltakere ble inkludert i studien. Median skår ble brukt som mål på læringsutbytte. Deltakernes skår var signifikant høyere for alle de tre praktiske $\emptyset$ velsene etter gjennomført kurs sammenliknet med skår før kursdeltakelse ( $p<0,001)$.

Selvevalueringen indikerte at deltakerne følte seg mer kompetente etter gjennomført kurs.

FORTOLKNING Studien indikerer at BSS-kurset gir bedre basale kirurgiske ferdigheter. I mangel av tilsvarende kurs i grunnutdanningen bør det vurderes innført som obligatorisk i den kirurgiske utdanningen i Norge.

Tekniske ferdigheter er nødvendige for å kunne utøve kirurgi $(1,2)$. I Norge har leger i kirurgisk spesialistutdanning tradisjonelt tilegnet seg slike ferdigheter under veiledning på operasjonsstuene (3). Denne undervisningen har vært lite standardisert og det har vært begrenset rom for objektive tilbakemeldinger. Derfor har praktiske kurs, som krigskirurgikurset og ATLS-kurset (Advanced Trauma Life Support), fătt økende betydning $\mathrm{i}$ spesialistutdanningen og er nå obligatoriske for spesialiteten generell kirurgi (4).

Sommeren 2009 ble Basic Surgical Skills-kurset (BSS-kurset) etablert i Norge av Oslo universitetssykehus, Ullevål og Norsk kirurgisk forening (3). Kurset ble opprinnelig utviklet av Royal Colleges of Surgeons (RCS) for å forbedre den kirurgiske grunnutdanningen. I Storbritannia må kurset gjennomføres i løpet av det første året av spesialistutdanningen. Målet med kurset er å lære deltakerne én sikker måte å utføre grunnleggende kirurgiske prosedyrer på (5). Det består av 14 øvelser som dekker emner fra kirurgisk håndvask og steril påkledning til tekniske ferdigheter som kirurgiske knuter, suturteknikker, tarmanastomoser, sårrevisjon og laparoskopiøvelser (6).

Denne studien ble gjennomført for å evaluere læringsutbyttet av BSS-kurset.

\section{Materiale og metode}

BSS-kurset ble annonsert på Legeforeningens nettsider, og søkerne ble tildelt plass fortløpende. Deltakere ved fire påfølgende kurs arrangert av Oslo universitetssykehus, Ullevål, i årene 2009-11 ble spurt om å delta i studien. De ble tilsendt skriftlig informasjon om studien på forhånd og ga muntlig samtykke til deltakelse første kursdag. Engelsk- språklig kurshåndbok og kurs-DVD utarbeidet av Royal Colleges of Surgeons samt studieinformasjon ble tilsendt deltakerne før kursstart (6).

Alle instruktørene hadde gjennomgått instruktørkurs og ble informert om studien og opplært i bruk av evalueringsverktøyene.

Deltakerne ble testet i de samme tre praktiske øvelsene umiddelbart før og etter kurset. Læringsutbyttet ble definert som differansen mellom skår etter og før kurset. Oppgavene var:

- Øvelse 1. Eksisjon av nævus og hudlukking (grisehud eller kunstig hudmodell)

- Øvelse 2. Omstikking av krøskar (grisetarmpreparat)

- Øvelse 3. Laparoskopisimulatorøvelse hvor deltakerne forte en gumminål med tråd gjennom ti ringer plassert i forskjellige vinkler, i en bestemt rekkefølge

Øvelsene ble valgt av hensyn til gjennomførbarhet og fordi de representerer helt grunnleggende prinsipper i kirurgien. Øvelse 1 og øvelse 2 ble skåret ved bruk av Objective Structured Assessment of Technical Skills (OSATS) $(7,8)$. OSATS-instrumentet har rapportert høy reliabilitet og validitet og består av sjekklister og Global Rating Scale (GRS) $(2,7)$. Sjekklistene er oppgavespesifikke med en punktvis beskrivelse av trinnene i hver prosedyre. Ved hjelp av GRS-skåring vurderes generelle ferdigheter som vevshåndtering, bevegelsesøkonomi, valg og håndtering av instrumenter samt kjennskap til og gjennomføring av prosedyren. Maksimal skår for øvelse 1 og øvelse 2 var henholdsvis 42 og 39 poeng. I øvelse 3 ble deltakerne vurdert ut fra anvendt tid per hinder (se mansoorappendiks).

Deltakerne skåret egne ferdigheter før og

\author{
Saira Mauland Mansoor \\ Oslo universitetssykehus, Ullevål \\ Jon-Anders Tunold \\ j.a.tunold@gmail.com \\ Diakonhjemmet Sykehus

\section{Pål Aksel Næss} \\ Avdeling for traumatologi \\ Erik Trondsen \\ Avdeling for gastro- og barnekirurgi \\ Christine Gaarder \\ Avdeling for traumatologi \\ Jorunn Skattum \\ Avdeling for gastro- og barnekirurgi \\ Oslo universitetssykehus, Ullevål
}

Podkast på www.tidsskriftet.no

Appendiks på www.tidsskriftet.no/

mansoorappendiks

> Se lederartikkel side 912

\section{HOVEDBUDSKAP}

Basic Surgical Skills-kurset (BSS) er praktisk opplæring i grunnleggende kirurgiske ferdigheter

Deltakerne på fire påfølgende kurs ble testet i praktiske øvelser før og etter gjennomført kurs, og prestasjonene ble blant annet målt med OSATS

Deltakerne utførte øvelsene signifikant bedre etter gjennomført kurs

BSS-kurset egner seg til praktisk kirurgisk opplæring 


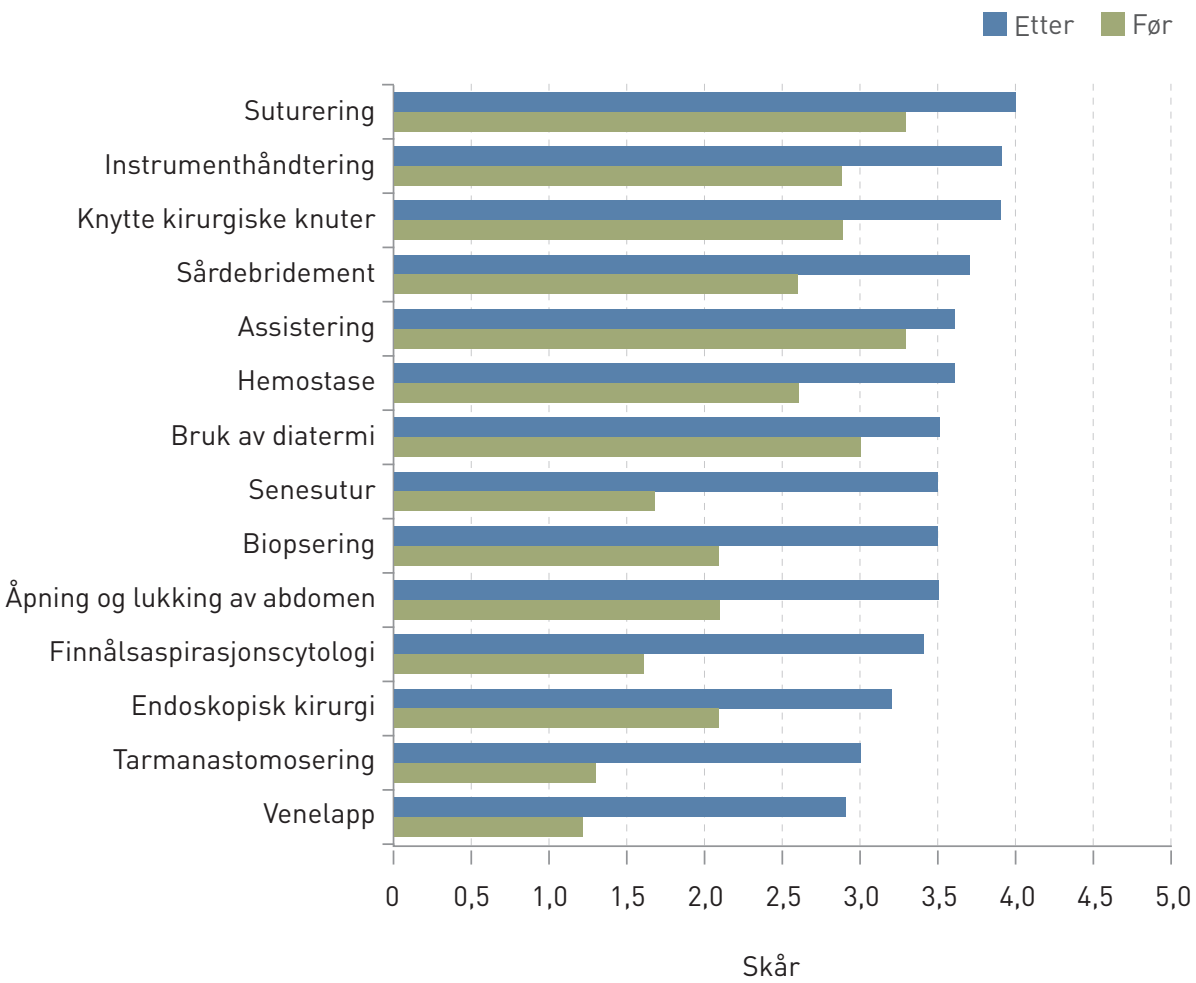

Figur 1 Selvevalueringsskjema førog etter kurset for de 14 underviste ferdighetene, med gjennomsnittlig skår før og etter kurset (basert på Likert-skala med gradering 1-5, der 1 betyr ingen ferdighet og 5 indikerer gode ferdigheter)

Tabell 1 Før-og-etter-skår for tre utvalgte praktiske øvelser ( $\mathrm{n}=57$ )

\begin{tabular}{|c|c|c|c|c|c|c|}
\hline \multirow{3}{*}{$\begin{array}{l}\text { Øvelse } \\
\text { Eksisjon av nævus } \\
\text { og hudlukking }\end{array}$} & \multirow{3}{*}{$\begin{array}{l}\text { Verktøy } \\
\text { Sjekkliste } \\
\text { Global Rating Scale }\end{array}$} & \multirow{2}{*}{\multicolumn{2}{|c|}{$\frac{\text { Skår før }}{\text { Median (KI) }}$}} & \multirow{2}{*}{\multicolumn{2}{|c|}{$\begin{array}{l}\text { Skår etter } \\
\text { Median (KI) }\end{array}$}} & \multirow{3}{*}{$\begin{array}{l}\text { P-verdi } \\
<0,001 \\
<0,001\end{array}$} \\
\hline & & & & & & \\
\hline & & $\begin{array}{r}9,0 \\
18,0\end{array}$ & $\begin{array}{r}(8,1-9,7) \\
(17,1-19,8)\end{array}$ & $\begin{array}{l}11,0 \\
23,0\end{array}$ & $\begin{array}{l}(10,1-11,3) \\
(22,3-24,8)\end{array}$ & \\
\hline Omstikking av krøskar & $\begin{array}{l}\text { Sjekkliste } \\
\text { Global Rating Scale }\end{array}$ & $\begin{array}{r}5,0 \\
16,5\end{array}$ & $\begin{array}{r}(4,4-6,2) \\
(15,3-18,8)\end{array}$ & $\begin{array}{r}8,0 \\
23,0\end{array}$ & $\begin{array}{r}(7,0-8,1) \\
(20,8-24,0)\end{array}$ & $\begin{array}{l}<0,001 \\
<0,001\end{array}$ \\
\hline $\begin{array}{l}\text { Laparaskopisk } \\
\text { hinderløype }\end{array}$ & Minutter per hinder & 0,8 & $(0,7-1,1)$ & 0,5 & $(0,5-0,6)$ & $<0,001$ \\
\hline
\end{tabular}

etter kurset for de 14 underviste ferdighetene på en Likert-skala fra 1 til 5, hvor 1 representerer ingen ferdighet og 5 representerer gode ferdigheter (9). For å vurdere om tidligere erfaring påvirket grad av forbedring ble resultatene beregnet for tre grupper stratifisert etter varigheten av tidligere erfaring, henholdsvis $0-6$ måneder, 6-12 måneder og $>12$ måneder, og så sammenliknet.

\section{Statistikk}

Dataene var ikke normalfordelte. Vi benyttet ikke-parametriske tester. Skår etter og før kurs for gruppen av deltakere ble sammenliknet med Wilcoxons test. Kruskal-Wallistest ble brukt til å vurdere om varigheten av kirurgisk erfaring innvirket på læringsutbyttet. Signifikansnivået ble satt til 0,05. De statistiske analysene ble utført i SPSS versjon 19 (IBM, USA).

\section{Resultater}

Totalt 57 av 65 kursdeltakere (88\%) samtykket i å delta i studien. Deltakerne var leger i spesialisering med kirurgisk erfaring som varierte fra 1 til 40 måneder, gjennomsnittlig 13 måneder.
Den selvevaluerte kompetanse for de 14 underviste ferdighetene var bedre på samtlige punkter etter gjennomført kurs (fig 1). Deltakerne presterte samlet bedre på de tre praktiske testene etter gjennomført kurs (tab 1). Læringsutbyttet av kurset var uavhengig av varigheten av kirurgisk erfaring for de tre praktiske testene $(\mathrm{p}=0,9)$.

\section{Diskusjon}

Vurdert ut fra skåringsresultatene bedret kursdeltakerne sine tekniske ferdigheter ved å gjennomføre BSS-kurset. Forbedringen var, noe overraskende, uavhengig av deltakernes kirurgiske erfaring. Vi forventet at deltakere med liten erfaring ville ha større utbytte av et basalkirurgisk kurs enn deltakere med lengre erfaring.

Den selvevaluert kompetansen økte etter gjennomført kurs, som vist i tidligere studier $(9,10)$. Økningen var lavest for ferdighetene «bruk av diatermi» og «utøvelse av assistanse», som kun ble undervist teoretisk (fig 1). Dette kan indikere at praktisk undervisning bør supplere teoretisk undervisning av tekniske ferdigheter.

$\AA$ evaluere grunnleggende laparoskopiske ferdigheter kun ved tidsforbruk per hinder har klare begrensninger. Funnene våre samsvarer imidlertid med resultater fra studier hvor flere variabler er undersøkt $(11,12)$. Studier har vist at simulatortrening er bedre enn tradisjonell lærebokundervisning og at ferdigheter ervervet på simulatorer er overførbare til operasjonsstuen $(11,13-18)$.

For en vellykket kirurgisk pasientbehandling må operatøren vedlikeholde sine praktiske ferdigheter. Flere studier viser at jevnlig trening kreves for å opprettholde nivået $(10,12,19)$. I vår studie har vi målt umiddelbare ferdigheter, og resultatene sier ikke noe om eventuell langtidseffekt. Det hadde også vært ønskelig med en kontrollgruppe for å undersøke effekten nærmere, men det var ikke praktisk gjennomførbart. Studien har også et begrenset antall deltakere, hvilket kan ha påvirket resultatene.

\section{Konklusjon}

Ferdighetene i tre basale kirurgiske teknikker ble signifikant bedre etter gjennomført BSS-kurs. Grad av kirurgisk erfaring syntes ikke å påvirke resultatet. Studien indikerer at BSS-kurset tilfører en relevant læringsressurs til den kirurgiske spesialiseringen i Norge. 


\section{Saira Mauland Mansoor (f. 1987)}

er cand.med. og turnuslege.

Forfatter har fylt ut ICMJE-skjemaet og oppgir ingen interessekonflikter.

\section{Jon-Anders Tunold (f. 1987)}

er cand.med. og turnuslege.

Forfatter har fylt ut ICMJE-skjemaet og oppgir ingen interessekonflikter.

\section{Pål Aksel Næss (f. 1958)}

er dr.med. og spesialist i generell kirurgi og i barnekirurgi.

Forfatter har fylt ut ICMJE-skjemaet og oppgir ingen interessekonflikter.

\section{Erik Trondsen (f. 1947)}

er dr.med. og spesialist i generell kirurgi og i gastrokirurgi.

Forfatter har fylt ut ICMJE-skjemaet og oppgir ingen interessekonflikter.

\section{Christine Gaarder (f. 1964)}

er dr.med. og spesialist i generell kirurgi og i gastrokirurgi. Hun er leder for en avdeling med betydelig forsknings- og undervisningsaktivitet innen traumatologi.

Forfatter har fylt ut ICMJE-skjemaet og oppgir ingen interessekonflikter.

\section{Jorunn Skattum (f. 1971)}

er dr.med. og spesialist i generell kirurgi og i gastrokirurgi.

Forfatter har fylt ut ICMJE-skjemaet og oppgir ingen interessekonflikter.

\section{Litteratur}

1. Moorthy K, Munz Y, Sarker SK et al. Objective assessment of technical skills in surgery. BMJ 2003; 327: 1032-7.

2. Reznick R, Regehr G, MacRae H et al. Testing technical skill via an innovative «bench station» examination. Am J Surg 1997: 173: 226-30.

3. Røsok B. RCSs Basic Surgical Skills kurs etableres i Norge. Kirurgen 2008; 4: 36.

4. Generell kirurgi - nye regler. Oslo: Helsedirektoratet, 2010. www.helsedirektoratet.no/ helsepersonell/spesialistgodkjenning/lege/ Documents/Generell\%20kirurgi\%20-\%20 nye\%20regler.pdf (26.11.2013)

5. Thomas WE. The basic surgical skill course: a 10-year success story. Ann R Coll Surg Engl 2007: 89: $90-1$

6. Thomas B, McCloy R. Intercollegiate Basic Surgical Skills Course participant handbook. 4. utg. London: The Royal College of Surgeons of England, 2007.

7. Martin JA, Regehr G, Reznick R et al. Objective structured assessment of technical skill (OSATS) for surgical residents. Br J Surg 1997; 84: 273-8.

8. Chipman JG, Schmitz CC. Using objective structured assessment of technical skills to evaluate a basic skills simulation curriculum for first-year surgical residents. J Am Coll Surg 2009; 209: 364-70.

9. Gaarder C, Naess PA, Buanes T et al. Advanced surgical trauma care training with a live porcine model. Injury 2005; 36: 718-24

10. Furnée EJB, van Empel PJ, Mahdavian Delavary B et al. Evaluation of a technical skills training program in surgical residents. J Laparoendosc Adv Surg Tech A 2009; 19: 615-21

11. Sturm LP, Windsor JA, Cosman PH et al. A systematic review of skills transfer after surgical simulation training. Ann Surg 2008; 248: 166-79.

12. Torkington J, Smith SGT, Rees B et al. The role of the basic surgical skills course in the acquisition and retention of laparoscopic skill. Surg Endosc 2001; 15: $1071-5$

13. Reznick RK, MacRae H. Teaching surgical skills changes in the wind. N Engl J Med 2006; 355 2664-9

14. Palter VN, Grantcharov T, Harvey A et al. Ex vivo technical skills training transfers to the operating room and enhances cognitive learning: a randomized controlled trial. Ann Surg 2011: 253: 886-9.

15. Anastakis DJ, Regehr G, Reznick RK et al. Assessment of technical skills transfer from the bench training model to the human model. Am J Surg 1999: 177: 167-70.

16. Stelzer MK, Abdel MP, Sloan MP et al. Dry lab practice leads to improved laparoscopic performance in the operating room. J Surg Res 2009; 154: $163-6$

17. Gurusamy KS, Aggarwal R, Palanivelu L et al. Virtual reality training for surgical trainees in laparoscopic surgery. Cochrane Database Syst Rev 2009; 21: CD006575.

18. Korndorffer JR Jr, Dunne JB, Sierra R et al. Simulator training for laparoscopic suturing using performance goals translates to the operating room. J Am Coll Surg 2005; 201: 23 -9.

19. Parent RJ, Plerhoples TA, Long EE et al. Early, intermediate, and late effects of a surgical skills «boot camp» on an objective structured assessment of technical skills: a randomized controlled study. J Am Coll Surg 2010; 210: 984-9.

Mottatt 2.6. 2013, første revisjon innsendt 12.1. 2014, godkjent 21.2. 2014. Redaktør: Tor Rosness. 